2016-06

\title{
Activation of multiple growth factor signalling pathways is frequent in meningiomas
}

\section{Hilton, DA}

http://hdl.handle.net/10026.1/4621

\subsection{1/neup. 12266}

Neuropathology

Wiley

All content in PEARL is protected by copyright law. Author manuscripts are made available in accordance with publisher policies. Please cite only the published version using the details provided on the item record or document. In the absence of an open licence (e.g. Creative Commons), permissions for further reuse of content should be sought from the publisher or author. 
This is an Accepted Manuscript by Neuropathology on Sept 2015 ; First published online 10 Nov 2015; embargo 12 months

Full Title: Activation of multiple growth factor signalling pathways is frequent in meningiomas

Running title: Signalling molecules in meningiomas

Authors: David A Hilton ${ }^{1}$, Aditya Shivane ${ }^{1}$, Leanne Kirk ${ }^{1}$, Kayleigh Bassiri ${ }^{2}$, Doyo G Enki ${ }^{3}$, C Oliver Hanemann ${ }^{2}$.

Affiliations: 1. Department of Cellular and Anatomical Pathology, Derriford Hospital, Plymouth, PL6 8DH, UK. 2. Institute of Translational and Stratified Medicine, Plymouth University Peninsula Schools of Medicine \& Dentistry, Plymouth, PL6 8BU, UK. 3. Department of Biostatistics, Plymouth University Peninsula Schools of Medicine \& Dentistry, Plymouth, PL6 8BU, UK.

Corresponding author: Dr D A Hilton, Department of Cellular and Anatomical Pathology, Derriford Hospital, Plymouth PL6 8DH, UK. Email: davidhilton@nhs.net Tel: +44 (0)1752 431360, Fax : +44 (0)1752 763590 


\begin{abstract}
A minority of meningiomas are difficult to treat with surgery or radiotherapy, and chemotherapeutic alternatives are limited. This study aims to better understand pathways that are active in meningiomas, in order to direct future treatment strategies. We investigated the expression and activation of multiple growth factor receptors, their ligands and downstream signalling pathways in 30 meningiomas using immunohistochemistry. Expression was correlated with chromosome 22q loss. Membrane expression of VEGFR and PDGFR $\beta$ was seen in $83 \%$ of tumours, Axl in 70\%, EGFR in 50\% and IGFR in 47\%. Expression was similar in low and high grade tumours, but membrane EGFR expression was not seen in tumours showing chromosome 22q loss $(\mathrm{p}<0.05)$. Expression of ligands IGF, NRG, VEGF, Gas 6, and signalling proteins, Mek, Erk, Jnk and Akt, and pS6RP, was widespread. Western blot confirmed widespread Axl expression and supported selective expression of EGFR in NF2intact meningiomas. The majority of meningiomas express and show activation of multiple growth factor receptors and their signalling pathways, irrespective of tumour grade. In addition to previously reported receptors, Axl offers a new therapeutic target. The findings also suggest that anti-EGFR based therapies may be less effective in meningiomas with 22q loss.
\end{abstract}

Key words : Meningioma, NF2 gene, merlin, growth factor, protein kinase 


\section{INTRODUCTION}

Meningiomas represent the most common primary intracranial neoplasm accounting for up to $34 \%$ of all tumours ${ }^{1}$. Although many maybe effectively treated surgically, a significant number are either surgically inaccessible or recur, particularly the 20-35\% which are either histologically atypical or malignant ${ }^{2}$. In addition, in approximately $10 \%$ of cases, meningiomas are multiple, particularly in familial tumour syndromes such as neurofibromatosis type 2 . Treatment of recurrent, multiple and surgically inaccessible tumours is difficult as chemotherapeutic regimes are of limited benefit ${ }^{3}$ and radiotherapy is associated with significant morbidity in a proportion of patients, even when given stereotactically ${ }^{4}$. Chromosome $22 \mathrm{q}$ losses are a common abnormality occurring in approximately $60 \%$ of sporadic tumours, most of which have been shown to also have mutations or methylation of the remaining neurofibromatosis type 2 (NF2) gene locus, leading to gene inactivation ${ }^{5,6}$. Much work has been done by ourselves and others on the function of the NF2 gene product Merlin, and how its loss leads to expression of a number of growth factors and their downstream signalling pathways ${ }^{7-9}$. Although most of this work has been carried out in relation to schwannomas, the findings suggest that Merlin-deficient tumours may be susceptible to a number of new therapeutic strategies directed at components of these pathways ${ }^{10}$. Recently a number of other genes, including AKT1, SMO, TRAF7, KLF4 and SMARCB1 have been shown to be defective in NF2-intact meningiomas ${ }^{11,12}$, but it is not clear whether this group of meningiomas differ in their pathway activation. The aim of the current study is to broadly assess the expression of a number of these growth factors, their receptors including their phosphorylation status, and downstream signalling molecules, in meningiomas of all grades (see Figure 1). In addition, we have compared a group of meningiomas known to have a high rate of NF2 gene inactivation, with meningiomas known to have a low rate ${ }^{5,13-15}$, in order to assess whether expression of these markers differs significantly between these two groups, and 
also compared expression with WHO Grade II and III meningiomas and non-neoplastic meninges.

\section{MATERIALS AND METHODS}

\section{Cases and tissue samples}

Local research ethics approval was obtained for the study. Formalin fixed paraffin embedded tissue samples from 30 meningiomas were retrieved from the archives of the Department of Cellular \& Anatomical Pathology, Derriford Hospital, Plymouth, UK. Cases were identified following a SNOMED search of the histology archives. 20 tumours were of WHO Grade I histological subtype and were selected to include 10 cases associated with a high rate of NF2 gene abnormalities (fibroblastic meningiomas, transitional meningiomas and meningiomas in patients with neurofibromatosis type 2) and 10 cases with a low rate of NF2 gene mutations (secretory meningiomas and meningothelial meningiomas). In addition 10 high grade meningiomas (5 atypical 5 anaplastic meningiomas) were included. 10 cortical brain biopsies including strips of arachnoid, acted as controls.

\section{Immunohistochemistry}

$4 \mu \mathrm{m}$ paraffin sections were de-waxed, re-hydrated and incubated with primary antibodies at room temperature overnight using the antigen retrieval methods and titres indicated below, as previously described ${ }^{16,17}$. Antibodies to the following growth factors and receptors were examined: phosphorylated platelet-derived growth factor receptor $\beta$ (pPDGFR $\beta$, Y857, Abcam, 1:800, 30 minutes EDTA pH9.0 and Y751, Abcam, 1:1000, 30 minutes EDTA); phosphorylated insulin-like growth factor 1 receptor (pIGF1R, Abcam, 1:50, 30 minutes citrate pH6.0); insulin-like growth factor 1 (IGF1, Abcam, 1:200, 30 minutes citrate pH6); insulin-like 
growth factor 2 (IGF2, Abcam, 1:250, 30 minutes citrate $\mathrm{pH} 6$ ); phosphorylated human epidermal growth factor receptor 2 (pErbB2, Cell Signalling, 1:50, 10 minutes trypsin); neuregulin 1 (NRG, Abcam, 1:70, 30 minutes EDTA pH9.0); phosphorylated human epidermal growth factor receptor 1 (pEGFR, Y845, R\&D systems, 1:200, 30 minutes EDTA pH9.0); phosphorylated vascular endothelial growth factor receptor 1 (VEGFR1p, Abcam, 1:100, 30 minutes EDTA pH9.0); phosphorylated vascular endothelial growth factor receptor 2 (VEGFR2p, Abcam, 1:100, 30 minutes EDTA pH9.0). Antibodies to the following protein kinases and signalling molecules were used; pMek (Cell Signalling, 1:600, 30 minutes EDTA pH9.0); mitogen activated protein kinase (Erk/MAPK, Abcam,1:500, 30 minutes EDTA pH9.0); phosphorylated mitogen activated protein kinase (pErk/MAPK, Promega, 1:500, 30 minutes EDTA pH9.0); pAkt (Santa Cruz, 1:100, 20 minutes DAKO antigen retrieval solution); pJnk (Cell Signalling, 1:100, 20 minutes DAKO antigen retrieval solution); Axl (R\&D systems, 1:75, 30 minutes EDTA pH9.0); pAxl (R\&D systems, 1:7500, 10 minutes EDTA pH9.0); Mer (Abnova, 1:100, 20 minutes DAKO antigen retrieval solution); growth arrest specific 6 (Gas 6, Sigma, 1:500, 30 minutes EDTA pH9.0); phosphorylated S6 ribosomal protein (pS6RP, Cell Signalling, 1:1000, 30 minutes EDTA pH9.0).

Avidin-biotin blocking solution was used to block non-specific signal with EDTA pretreatment. Sections were incubated with appropriate biotin-labelled secondary antibody and with horseradish peroxidase for detection using Vectashield Elite according to the manufacturer's protocol. As a control, sections were incubated with omission of the primary antibody. The immunohistochemical results were reviewed by two neuropathologists (DAH and AS). With some antibodies there was stronger immunoreactivity at the periphery of tissue fragments, which was presumed to be related to better preservation of antigen due to more rapid fixation. Semiquantitaive assessment of the proportion of the tumour sample that stained positive was undertaken and scored as follows: 0 if less than 5\% of tumour cells showed 
immunoreactivity; 1 if $5-25 \%$ of the tumour was positive; 2 if $26-50 \%$ was positive; 3 if $51-$ $75 \%$ was positive and 4 if $>75 \%$ was positive. Membrane staining was generally very focal within the tumour, so this was scored as being either present or absent for each of the membrane receptors.

\section{Western blot analysis}

Primary cell cultures, derived from 6 meningiomas, were grown in T25 flasks (Greiner BioOne) until confluent, lysed with RIPA buffer and protein concentrations were determined with a detergent compatible protein assay (Bio-Rad Laboratories, Hercules, CA). 20ug of each sample was separated a pre-cast 4-15\% gradient gel (Bio-Rad). Blocking was done in 5\% milk, $2 \%$ BSA in $0.1 \%$ tween in TBS for 1 hour at RT. Membranes were incubated with anti-NF2 (Cell Signalling, 1:1000) and either anti-pAXL (1 $\mu \mathrm{g} / \mathrm{ml}, \mathrm{R}$ and D systems) or anti-pErbB2 (Cell Signalling,1:50). GAPDH was used as a loading control in all cases (1: 20000, Millipore) before incubation with appropriate HRP-conjugated secondary antibodies (Bio-Rad). ECL (Amersham Biosciences) was used for detection. Insufficient lysate was obtained from some tumours to allow both pAxl and pErbB2 to be assessed.

\section{In situ hybridisation}

Fluorescent in situ hybridisation (FISH) was undertaken using a probe to chromosome arm 22q as a marker of chromosome 22 loss (Vysis LSI 22q, BCR, spectrum green probe). FISH was carried out largely according to the manufacturer's instructions. Briefly dewaxed $5 \mu \mathrm{m}$ paraffin sections were heated in a pressure cooker for 5 minutes in citrate buffer at pH6 and then digested in $0.4 \%$ pepsin at $37^{\circ} \mathrm{C}$ for 10 minutes. Dehydrated sections were then co-denatured with probe at $75^{\circ} \mathrm{C}$ for 10 minutes and hybridised overnight. Unbound probe was washed off using the manufacturer's wash solutions and the sections were mounted with DAPI antifade 
solution. The sections were viewed with a Leica DMRB fluorescent microscope using an x100 objective and spectrum green filters. A minimum of 100 tumour cell nuclei were assessed and tumours with greater than $50 \%$ of cells showing a single signal were regarded as showing monosomy. All sections were analysed by a pathologist blind to the original diagnosis and any of the other results.

\section{Statistical analysis}

Qualitative variables were binary coded and, along with the quantitative expression scores, read into SPSS datasheet for statistical analysis. Pearson Chi-Square was used to test for association between each of the meningioma groups and the nominal variables. Fisher's exact test was used when the expected counts were small. For quantitative variables, possible differences in the expression between groups of meningioma were tested using non-parametric (Mann-Whitney) test. A 5\% level of significance was considered in all tests and p-values were reported whenever appropriate. Statistical analysis was carried out using SPSS V21.0.

\section{RESULTS}

\section{Growth factor receptors and ligands}

Expression of IGF1 and 2 was seen in varying intensities in the cytoplasm of all tumours. IGF1 and IGF2 gave granular cytoplasmic and nuclear immunoreactivity in tumour cells, whereas pIGF1R was predominantly nuclear in many tumour cells, with focal membrane staining in some (Figure 2A and B). Neuregulin gave weak, diffuse or granular cytoplasmic immunoreactivity in many tumour cells (Figure 2C), but was also seen in normal meninges. pEGFR and pErbB2 immunoreactivity was predominantly cytoplasmic in both tumours and control tissue, with focal areas of membrane staining in some of tumour cells (Figure 2D and E). Relatively weak cytoplasmic and membrane expression of Gas 6 was seen focally in about half of the tumours, and some of the non-neoplastic leptopmeninges. Looking at TAM 
receptors, Axl and pAxl gave widespread, but generally weak, diffuse cytoplasmic staining, and in some tumours variable membrane and nuclear staining. pAxl produced the more intense membrane (Figure 2F) and nuclear immunoreactivity. Mer expression was variable within the cytoplasm and nuclei of tumour cells, and rarely seen in non-neoplastic leptomeninges, but was strong within infiltrating macrophages and mast cells.

pPDGFR $\beta$ immunoreactivity was widespread in tumour nuclei and diffusely within the cytoplasm, but more localised and often granular in tumour membranes and endothelial cells. pPDGFR $\beta$ immunoreactivity was more intense with the antibody recognising phosphorylation at Y857 than the Y751 (Figure 3A). Antibodies to pVEGFR1p and pVEGFR2p gave very similar results with a mixture of nuclear, cytoplasmic and coarse granular membrane immunoreactivity in both tumour cells and vasculature (Figure 3B). Non-neoplastic leptomeninges showed some nuclear and cytoplasmic immunoreactivity with these receptor antibodies, but did not show any membrane immunoreactivity, apart from one case showing focal pVEGFR2p membrane immunoreactivity. A summary of the proportion of tumours showing growth factor receptor membrane immunoreactivity is shown in the table.

\section{Activation of downstream signalling pathways}

Analysing downstream signalling pathways, pMek gave strong nuclear and variable cytoplasmic immunoreactivity (Figure 4A). Widespread Erk immunoreactivity, with the nonphosphorylated form being predominantly cytoplasmic, whereas the phosphorylated form was predominantly nuclear in localisation with patchy cytoplasmic and membrane immunoreactivity (Figure 4B). In several tumours pErk showed areas of very strong immunoreactivity intermingled with areas of tumour which were negative. Control leptomeninges showed patchy cytoplasmic and nuclear pErk immunoreactivity. pJnk immunoreactivity was weak and patchy within the nuclei and cytoplasmic in both the tumours 
and control leptomeninges. pAkt immunoreactivity was weak and patchy, but sometimes strong within the nuclei in both the tumours (Figure 4C) and control leptomeninges. pS6RP expression was cytoplasmic, sometimes perinuclear in distribution (Figure 4D). pS6RP immunoreactivity was also seen in endothelial cells, macrophages, and weak staining was seen in some of the control leptomeninges.

No significant staining was seen following with omission of the primary antibodies.

In view of the novel finding of pAxl expression in the majority of meningiomas and the selective membrane expression of pErbB2 in tumours without 22q loss, these proteins were further analysed by Western blot using primary meningioma cell cultures. The findings supported the immunohistochemical observations with widespread pAxl expression in NF2intact and deficient meningiomas, and limited expression pErbB2 to one NF2-intact meningioma (Figure 5A and B).

FISH analysis revealed loss from chromosome arm 22q, in $70 \%$ of the group of meningiomas expected to have a high rate of $N F 2$ gene inactivation (fibroblastic meningiomas, transitional meningiomas and meningiomas in patients with neurofibromatosis type 2), and in $10 \%$ group of meningiomas expected to have a low rate of $N F 2$ gene inactivation (secretory meningiomas and meningothelial meningiomas). 4 out of 10 high grade meningiomas showed 22q loss. Polyploidy was noted in several of the tumours. Semi-quantitative scoring of staining intensity and distribution was difficult due to variable tissue preservation of antigen, but was scored for each of the markers, and in addition for the majority of the growth factor receptors the presence or absence of membrane immunoreactivity was also noted (see Appendix for scores). There were significant differences in intensity of expression of many of the markers between tumour and non-neoplastic meninges (pS6RP, pAxl, membrane staining of pIGFR and pErbB2 p<0.05; 
IGF1, Erk and membrane staining of Axl p<0.005; pEGFR, Mer, pVEGFR1p, pVEGFR2p and membrane staining of pPDGFR $\beta Y 857$, pVEGFR1p, pVEGFR2p and $p A x 1 \mathrm{p}<0.001$ ). When comparing WHO grade I with WHO grade II/III tumours there were significant reductions in the intensity of non-membrane expression of some of the receptors in higher grade tumours ( $\mathrm{pErbB} 2$, Mer $\mathrm{p}<0.001$; $\mathrm{pVEGFR2} \mathrm{p} \mathrm{p}<0.005$ ), reduction in membrane expression of pVEGFR1p $(\mathrm{p}<0.05)$, and increased non-membrane expression of pPDGFR $\beta Y 751(\mathrm{p}<0.005)$. No other differences were found between tumour grades. An increase pErk and pS6RP immunoreactivity was seen $(\mathrm{P}<0.05)$ in tumours with $22 \mathrm{q}$ loss. Assessment of the clinical relevance of these semiquantitative differences in immunoreactivity is unclear due to the variation in antigen preservation within tissue samples. However, a clear difference between 22q-intact and deleted cases was that membrane expression of pEGFR and pErbB2 was only seen in tumours without $22 \mathrm{q}$ loss ( $<<0.05$ and 0.005 respectively, see Table).

\section{DISCUSSION}

Previous studies have looked at the expression of some of these markers in meningiomas, however, none has looked at the wide range that we assessed. In addition we have correlated expression with presumed NF2 gene status, and where possible, we have used antibodies to the activated (phosphorylated) forms of receptors, and also looked at expression of ligands and downstream signalling pathways. Our findings indicate that most meningiomas co-express multiple growth factors in their phosphorylated form along with the downstream pathways, suggesting that expression is functionally significant. Although expression of many of the growth factors was similar in tumours with and without $22 \mathrm{q}$ loss, there was evidence of differential expression epidermal growth factor receptors between these groups.

Previous studies looking at the expression of platelet derived growth factor and it's receptor in meningiomas have demonstrated the widespread expression of these molecules in most 
meningiomas ${ }^{18,19}$, particularly the beta receptor, in meningiomas of all grades ${ }^{20}$. In addition there is in vitro evidence suggesting autocrine activity ${ }^{21}$ which may be blocked with specific inhibitors $^{22}$. Other studies have also shown a high rate expression of insulin-like growth factor and its receptor ${ }^{23-25}$, and there is in vitro evidence of its functionality in meningioma cell cultures ${ }^{24}$. Rates of expression of epidermal growth factor and its receptor are more variable, although most studies have found expression in the majority (45-100\%) of cases of all grades 24-29. ErbB2 protein and gene over-expression have been reported in between 2 and $86 \%$ of meningiomas ${ }^{30-32}$. Vascular endothelial growth factor and its receptors have also been shown to be present in the majority of meningiomas of all grades, with degree of expression correlating with peritumoural oedema ${ }^{25,33}$. A recent study has suggested that inhibition of these pathways may slow tumour cell migration and proliferation ${ }^{34}$. The findings in our study support the findings in previous reports, but in addition indicate that co-expression of multiple and, importantly, activated growth factor-receptor pathways, is a common feature of meningiomas. Most previous studies have assessed both cytoplasmic and membrane receptor immunoreactivity, and although the significance of the nuclear immunoreactivity is unclear, this has also been seen in previous studies on meningiomas ${ }^{33,35}$, and nuclear localisation has also been reported for a growth factor receptors in non-neoplastic tissues ${ }^{36,37}$.

Relatively few previous studies have looked at the expression of downstream signalling molecules, in particular protein kinases, in meningiomas ${ }^{38,39}$, but their findings suggest that levels of expression is higher in WHO Grade II and III tumours. Our findings have demonstrated the expression of phosphorylated Jnk and Mek, in addition to Erk, pS6RP and Akt, in the majority of meningiomas of all grades. The expression of Ras/Raf/Mek/Erk, the $\mathrm{Pi} 3 \mathrm{~K} / \mathrm{Akt} / \mathrm{mTOR} / \mathrm{pS} 6 \mathrm{RP}$ signalling pathways supports the suggestion that the growth factors and their ligands are functional in meningiomas, a conclusion that is further supported by data 
to suggest that specific inhibition of these signalling pathways may reduce meningioma cell proliferation in vitro ${ }^{38,40}$.

Chromosome $22 \mathrm{q} / N F 2$ gene abnormalities occur in approximately $60 \%$ of sporadic meningiomas, which has been shown to correlate with reduced expression of merlin ${ }^{41-43}$, however, this varies with tumour subtype, with losses and/or NF2 mutations in 70-80\% of fibroblastic and transitional meningiomas, around 25\% meningothelial meningiomas, but rare in secretory meningiomas $5,15,44$. As we used archived samples we selected two groups of meningiomas with high and low rates of $N F 2$ gene abnormalities for comparison, of growth factor receptor expression. FISH, using a $300 \mathrm{~kb}$ probe to $22 \mathrm{q} 11.2$, showed evidence of loss in $7 / 10$ of the meningiomas expected to have a high rate of $N F 2$ gene abnormalities and 1/10 meningiomas expected to have a low rate. In the atypical/malignant subgroup, 4/10 showed evidence of $22 q$ loss. An interesting and unexpected finding was that membrane expression of epidermal growth factor receptors was only seen in meningiomas without $22 \mathrm{q}$ loss. Previous studies on meningiomas have not distinguished membrane from cytoplasmic immunoreactivity, however, membrane staining appears to be significant as a predictor of tumour response to anti-EGFR therapies treatment in breast tumours ${ }^{45}$. Although cytoplasmic expression of EGFR was seen in 9/11 tumours showing 22q loss, no membrane expression of either EGFR or ErbB2 was seen in this group. The reason for this observation and the higher levels of pErbB2 in tumours expressing merlin is unclear, and could be related directly to merlin or secondary to other genetic changes seen in meningiomas ${ }^{11,12}$. However, it is known that merlin interacts with ErbB2 at the cell membrane ${ }^{46}$ and may mediate cell-cell contact mediated inhibition of EGFR signalling by sequestering activated EGFR to the cell membrane ${ }^{47}$ and it has been shown that cells with merlin loss also have increased membrane expression of ErbB2 ${ }^{48}$. This differential expression may indicate a possibility for therapeutically relevant stratification as ErbB2 inhibitors are used clinically. A previous study 
which looked at the expression of the platelet derived growth factor and it's receptor and correlated expression with monosomy of chromosome 22 and, like us, did not find a significant relationship ${ }^{18}$. However, another recent study found that meningiomas with monosomy of chromosome 22 had higher levels of PDGFR $\beta$ than those without, and meningiomas with multiple chromosomal changes had reduced ErbB2 levels ${ }^{49}$, and although tumours with $22 \mathrm{q}$ loss had lower median levels of ErbB2 than diploid tumours, this was not statistically significant. Larger studies of well characterised genetic sub-groups of meningiomas will be required to confirm, and better understand, this relationship.

Axl expression has been shown to be important in a wide range of other tumours ${ }^{50-53}$, including merlin deficient tumours such as schwannomas and mesotheliomas ${ }^{50,54,55}$, but there are no data available for its potential role meningiomas. The frequent expression of Axl found in meningiomas in our study, suggests that further study of its potential role in meningioma growth is warranted, and if a functional role is confirmed then it offers further therapeutic options 56,57 .

These findings are strongly suggestive of a largely autocrine mediated activation of multiple growth factor receptors and their signalling pathways being significant in the growth of meningiomas. Activation of multiple pathways also suggests that combination therapy against multiple growth factors/receptors, or their common signalling pathways ${ }^{10,58}$ may be the most effective approach to treatment, and may explain the disappointing results of single pathway inhibitors such as the PDGFR inhibitor, imatinib mesylate ${ }^{59}$, VEGF inhibitor, bevacizumab ${ }^{60}$ and EGFR inhibitors, gefitinib and erolotinib ${ }^{61}$. The lack of membrane expression of pEGFR and $\mathrm{pErB} 2$ in tumours with loss of $22 \mathrm{q}$, suggests that this group of meningiomas may be less responsive to EGFR inhibitors. 


\section{Figure Legends}

\section{Fig. 1}

Diagram showing the relationships between the cell-surface receptor tyrosine kinases (PDGFR $\beta$, IGF-1R, ErbB2, VEGFR 1/2 and Axl), their ligands (PDGF, IGF-1, IGF-2, EGF, NRG, VEGF and Gas 6) and signal-transduction pathways (Mek1/2, Erk1/2, Jnk, PI3K/Akt/S6RP) (Black colour indicates proteins which were investigated in this study).

\section{Fig. 2}

Expression of ligands and receptors in meningiomas: widespread diffuse granular cytoplasmic IGF1 immunoreactivity (A) and strong nuclear and focal membrane pIGF1R immunoreactivity (B) within the same tumour; weak, diffuse cytoplasmic neuregulin immunoreactivity (C), both weak cytoplasmic and strong membrane pErbB2 immunoreactivity (D) and moderate cytoplasmic and membrane pEGFR immunoreactivity (E) in chromosome 22q-intact tumours; and strong membrane pAxl immunoreactivity $(\mathbf{F})$, which was seen in 22q-intact and deleted tumours. Scale bar $50 \mu \mathrm{m}$.

\section{Fig. 3}

Co-expression of pPDGFR $\beta$ (A) and pVEGFR2p (B) in a meningioma, weak nuclear and cytoplasmic tumour immunoreactivity, with patchy stronger coarse granular membrane immunoreactivity. Strong endothelial immunoreactivity is also seen. Scale bar $50 \mu \mathrm{m}$.

\section{Fig. 4}

Co-expression of multiple downstream transcription factors in a meningioma: Strong nuclear and weak cytoplasmic pMek immunoreactivity (A), focal strong nuclear, and weaker more diffuse cytoplasmic pErk immunoreactivity (B), strong nuclear pAkt immunoreactivity, (C) 
and diffuse granular cytoplasmic S6RP immunoreactivity (D). Scale bar $50 \mu \mathrm{m}$ A-C and $25 \mu \mathrm{m}$ D.

\section{Fig. 5}

Western blot analysis of primary meningioma cell cultures demonstrating variable intensity, but widespread, pAxl expression in all tumour samples (A). pErbB2 is only detected within one of two NF2 expressing tumours (B). GAPDH used as control and NF2 gene product, merlin, also demonstrated.

\section{Author contributions}

David Hilton: wrote first draft of the paper, contributed to study design and interpretation of immunocytochemical staining and FISH analysis. Aditya Shivane: contributed to final draft of the paper, contributed to study design and interpretation of immunocytochemical staining. Leanne Kirk: contributed to final draft of the paper and undertook all of the immunocytochemical staining and FISH. Kayleigh Bassiri: contributed to final draft of the paper and undertook all of the Western blot analyses. Oliver Hanemann: contributed to final draft of the paper, contributed to study design and interpretation of immunocytochemical staining.

Conflict of interest statement : None of the authors has any conflict of interest in relation to the work in this manuscript. 


\section{REFERENCES}

1. Wiemels J, Wrensch M, Claus EB. Epidemiology and etiology of meningioma. $J$ Neurooncol 2010;99;307-314.

2. Rogers L, Gilbert M, Vogelbaum MA. Intracranial meningiomas of atypical (WHO grade II) histology. J Neurooncol 2010;99;393-405.

3. Chamberlain MC. Hydroxyurea for recurrent surgery and radiation refractory highgrade meningioma. J Neurooncol 2012;107;315-321.

4. Pollock BE, Stafford SL, Link MJ, Garces YI, Foote RL. Stereotactic radiosurgery of World Health Organization grade II and III intracranial meningiomas: treatment results on the basis of a 22-year experience. Cancer 2012;118;1048-1054.

5. Wellenreuther R, Kraus JA, Lenartz D et al. Analysis of the neurofibromatosis 2 gene reveals molecular variants of meningioma. Am J Pathol 1995;146;827-832.

6. Lomas J, Bello MJ, Arjona D et al. Genetic and epigenetic alteration of the NF2 gene in sporadic meningiomas. Genes Chromosomes Cancer 2005;42;314-319.

7. Ammoun S, Schmid MC, Ristic N et al. The role of insulin-like growth factors signaling in merlin-deficient human schwannomas. Glia 2012;60;1721-1733.

8. Hanemann CO. Magic but treatable? Tumours due to loss of merlin. Brain 2008;131;606-615.

9. Curto M, McClatchey AI. Nf2/Merlin: a coordinator of receptor signalling and intercellular contact. Br J Cancer 2008;98;256-262.

10. Ammoun S, Hanemann CO. Emerging therapeutic targets in schwannomas and other merlin-deficient tumors. Nat Rev Neurol 2011;7;392-399.

11. Clark VE, Erson-Omay EZ, Serin A et al. Genomic analysis of non-NF2 meningiomas reveals mutations in TRAF7, KLF4, AKT1, and SMO. Science 2013;339;1077-1080.

12. Brastianos PK, Horowitz PM, Santagata S et al. Genomic sequencing of meningiomas identifies oncogenic SMO and AKT1 mutations. Nat Genet 2013;45;285-289.

13. Evans JJ, Jeun SS, Lee JH et al. Molecular alterations in the neurofibromatosis type 2 gene and its protein rarely occurring in meningothelial meningiomas. J Neurosurg 2001;94;111-117.

14. Kros J, de Greve K, van Tilborg A et al. NF2 status of meningiomas is associated with tumour localization and histology. J Pathol 2001;194;367-372.

15. Hartmann C, Sieberns J, Gehlhaar C, Simon M, Paulus W, von Deimling A. NF2 mutations in secretory and other rare variants of meningiomas. Brain Pathol 2006;16;15-19. 16. Hilton DA, Ristic N, Hanemann CO. Activation of ERK, AKT and JNK signalling pathways in human schwannomas in situ. Histopathology 2009;55;744-749.

17. Hanemann CO, Gabreels-Festen AA, Stoll G, Muller HW. Schwann cell differentiation in Charcot-Marie-Tooth disease type 1A (CMT1A): normal number of myelinating Schwann cells in young CMT1A patients and neural cell adhesion molecule expression in onion bulbs. Acta Neuropathol 1997;94;310-315.

18. Figarella-Branger D, Vagner-Capodano AM, Bouillot $\mathrm{P}$ et al. Platelet-derived growth factor (PDGF) and receptor (PDGFR) expression in human meningiomas: correlations with clinicopathological features and cytogenetic analysis. Neuropathol Appl Neurobiol 1994;20;439-447.

19. Maxwell M, Galanopoulos T, Hedley-Whyte ET, Black PM, Antoniades HN. Human meningiomas co-express platelet-derived growth factor (PDGF) and PDGF-receptor genes and their protein products. Int J Cancer 1990;46;16-21.

20. Nagashima G, Asai J, Suzuki R, Fujimoto T. Different distribution of c-myc and MIB-1 positive cells in malignant meningiomas with reference to TGFs, PDGF, and PgR expression. Brain Tumor Pathol 2001;18;1-5. 
21. Mauro A, Di Sapio A, Mocellini C, Schiffer D. Control of meningioma cell growth by platelet-derived growth factor (PDGF). J Neurol Sci 1995;131;135-143.

22. Schrell UM, Gauer S, Kiesewetter F et al. Inhibition of proliferation of human cerebral meningioma cells by suramin: effects on cell growth, cell cycle phases, extracellular growth factors, and PDGF-BB autocrine growth loop. J Neurosurg 1995;82;600-607.

23. Lichtor T, Kurpakus MA, Gurney ME. Differential expression of insulin-like growth factor II in human meningiomas. Neurosurgery 1991;29;405-409; discussion 409-410.

24. Kurihara M, Tokunaga Y, Tsutsumi K et al. Characterization of insulin-like growth factor I and epidermal growth factor receptors in meningioma. J Neurosurg 1989;71;538-544. 25. Baxter DS, Orrego A, Rosenfeld JV, Mathiesen T. An audit of immunohistochemical marker patterns in meningioma. J Clin Neurosci 2014;21;421-426.

26. Smith JS, Lal A, Harmon-Smith M, Bollen AW, McDermott MW. Association between absence of epidermal growth factor receptor immunoreactivity and poor prognosis in patients with atypical meningioma. J Neurosurg 2007;106;1034-1040.

27. Kuratsu JI, Seto H, Kochi M, Ushio Y. Expression of PDGF, PDGF-receptor, EGFreceptor and sex hormone receptors on meningioma. Acta Neurochir (Wien) 1994;131;289293.

28. Carroll RS, Black PM, Zhang J et al. Expression and activation of epidermal growth factor receptors in meningiomas. J Neurosurg 1997;87;315-323.

29. Wernicke AG, Dicker AP, Whiton M et al. Assessment of Epidermal Growth Factor Receptor (EGFR) expression in human meningioma. Radiat Oncol 2010;5;46.

30. Mahzouni P, Movahedipour M. An immunohistochemical study of HER2 expression in meningioma and its correlation with tumor grade. Pathol Res Pract 2012;208;221-224.

31. Loussouarn D, Brunon J, Avet-Loiseau H, Campone M, Mosnier JF. Prognostic value of HER2 expression in meningiomas: an immunohistochemical and fluorescence in situ hybridization study. Hum Pathol 2006;37;415-421.

32. Potti A, Panwalkar A, Langness E et al. Role of her-2/neu overexpression and clinical features at presentation as predictive factors in meningiomas. Am J Clin Oncol 2004;27;452456.

33. Otsuka S, Tamiya T, Ono Y et al. The relationship between peritumoral brain edema and the expression of vascular endothelial growth factor and its receptors in intracranial meningiomas. J Neurooncol 2004;70;349-357.

34. Pfister C, Pfrommer H, Tatagiba MS, Roser F. Vascular endothelial growth factor signals through platelet-derived growth factor receptor beta in meningiomas in vitro. $\mathrm{Br} J$ Cancer 2012;107;1702-1713.

35. Panagopoulos AT, Lancellotti CL, Veiga JC, de Aguiar PH, Colquhoun A. Expression of cell adhesion proteins and proteins related to angiogenesis and fatty acid metabolism in benign, atypical, and anaplastic meningiomas. J Neurooncol 2008;89;73-87.

36. Reigstad LJ, Martinez A, Varhaug JE, Lillehaug JR. Nuclear localisation of endogenous SUMO-1-modified PDGF-C in human thyroid tissue and cell lines. Exp Cell Res 2006;312;782-795.

37. Mukdsi JH, De Paul AL, Gutierrez S, Roth FD, Aoki A, Torres AI. Subcellular localisation of VEGF in different pituitary cells. Changes of its expression in oestrogen induced prolactinomas. J Mol Histol 2005;36;447-454.

38. Mawrin C, Sasse T, Kirches E et al. Different activation of mitogen-activated protein kinase and Akt signaling is associated with aggressive phenotype of human meningiomas. Clin Cancer Res 2005;11;4074-4082.

39. Johnson M, Toms S. Mitogenic signal transduction pathways in meningiomas: novel targets for meningioma chemotherapy? J Neuropathol Exp Neurol 2005;64;1029-1036. 
40. Johnson MD, Okedli E, Woodard A, Toms SA, Allen GS. Evidence for phosphatidylinositol 3-kinase-Akt-p7S6K pathway activation and transduction of mitogenic signals by platelet-derived growth factor in meningioma cells. J Neurosurg 2002;97;668-675. 41. Ruttledge MH, Xie YG, Han FY et al. Deletions on chromosome 22 in sporadic meningioma. Genes Chromosomes Cancer 1994;10;122-130.

42. Dumanski JP, Carlbom E, Collins VP, Nordenskjold M. Deletion mapping of a locus on human chromosome 22 involved in the oncogenesis of meningioma. Proc Natl Acad Sci U S A $1987 ; \mathbf{8 4} ; 9275-9279$.

43. Seizinger BR, de la Monte S, Atkins L, Gusella JF, Martuza RL. Molecular genetic approach to human meningioma: loss of genes on chromosome 22. Proc Natl Acad Sci U S A 1987;84;5419-5423.

44. Perry A, Cai DX, Scheithauer BW et al. Merlin, DAL-1, and progesterone receptor expression in clinicopathologic subsets of meningioma: a correlative immunohistochemical study of 175 cases. J Neuropathol Exp Neurol 2000;59;872-879.

45. Wolff AC, Hammond ME, Schwartz JN et al. American Society of Clinical Oncology/College of American Pathologists guideline recommendations for human epidermal growth factor receptor 2 testing in breast cancer. J Clin Oncol 2007;25;118-145.

46. Fernandez-Valle C, Tang Y, Ricard J et al. Paxillin binds schwannomin and regulates its density-dependent localization and effect on cell morphology. Nat Genet 2002;31;354-362. 47. Curto M, Cole BK, Lallemand D, Liu CH, McClatchey AI. Contact-dependent inhibition of EGFR signaling by Nf2/Merlin. J Cell Biol 2007;177;893-903.

48. Lallemand D, Manent J, Couvelard A et al. Merlin regulates transmembrane receptor accumulation and signaling at the plasma membrane in primary mouse Schwann cells and in human schwannomas. Oncogene 2009;28;854-865.

49. Domingues PH, Teodosio C, Otero A et al. The protein expression profile of meningioma cells is associated with distinct cytogenetic tumour subgroups. Neuropathol Appl Neurobiol 2014.

50. Pinato DJ, Mauri FA, Lloyd T et al. The expression of Axl receptor tyrosine kinase influences the tumour phenotype and clinical outcome of patients with malignant pleural mesothelioma. Br J Cancer 2013;108;621-628.

51. Han J, Tian R, Yong B et al. Gas6/Axl mediates tumor cell apoptosis, migration and invasion and predicts the clinical outcome of osteosarcoma patients. Biochem Biophys Res Commun 2013;435;493-500.

52. Dunne PD, McArt DG, Blayney JK et al. AXL is a key regulator of inherent and chemotherapy-induced invasion and predicts a poor clinical outcome in early-stage colon cancer. Clin Cancer Res 2014;20;164-175.

53. D'Alfonso TM, Hannah J, Chen Z, Liu Y, Zhou P, Shin SJ. Axl receptor tyrosine kinase expression in breast cancer. J Clin Pathol 2014;67;690-696.

54. Ammoun S, Provenzano L, Zhou L et al. Axl/Gas6/NFkappaB signalling in schwannoma pathological proliferation, adhesion and survival. Oncogene 2014;33;336-346. 55. Boin A, Couvelard A, Couderc $\mathrm{C}$ et al. Proteomic screening identifies a YAP-driven signaling network linked to tumor cell proliferation in human schwannomas. Neuro Oncol 2014.

56. Iida S, Miki Y, Suzuki T et al. Activation of AXL and antitumor effects of a monoclonal antibody to AXL in lung adenocarcinoma. Anticancer Res 2014;34;1821-1827.

57. Leconet W, Larbouret C, Chardes T et al. Preclinical validation of AXL receptor as a target for antibody-based pancreatic cancer immunotherapy. Oncogene 2013;Epub date: 18 November 2013.

58. Choy W, Kim W, Nagasawa D et al. The molecular genetics and tumor pathogenesis of meningiomas and the future directions of meningioma treatments. Neurosurg Focus 2011;30;E6. 
59. Wen PY, Yung WK, Lamborn KR et al. Phase II study of imatinib mesylate for recurrent meningiomas (North American Brain Tumor Consortium study 01-08). Neuro Oncol 2009;11;853-860.

60. Nunes FP, Merker VL, Jennings D et al. Bevacizumab treatment for meningiomas in NF2: a retrospective analysis of 15 patients. PLoS One 2013;8; 59941.

61. Norden AD, Raizer JJ, Abrey LE et al. Phase II trials of erlotinib or gefitinib in patients with recurrent meningioma. J Neurooncol 2010;96;211-217. 
